\title{
Optimization Method of Heating Furnace for Stirling Engine Heated by
}

\section{Natural Gas}

\author{
PENG Bo ${ }^{1, a}$, TIAN Junwei ${ }^{1, b}$ and,WANG qin ${ }^{1, c}, S U Y^{1, d}$, LEI Zhiqiang ${ }^{1, e}$ \\ 1 School of mechanical and electrical engineering, Xi'an Technological University, \\ Xi'an,710021,China \\ a624861983@qq.com, ${ }^{\text {b249460651@qq.com, }}{ }^{\mathrm{c}}$ 709972930@qq.com, ${ }^{\mathrm{d}}$ 45364159@qq.com, \\ e157893742@qq.com
}

\begin{abstract}
Keywords: Gas furnace; flat flame burner; radiant panel
Abstract. The Stirling engines are subjected to the poor heating quality and low output power. In order to overcome the problems, optimization method can be adopted, such as improving flat flame burner and increasing radiation plate, which can improve the efficiency of Stirling engine and increase the power output. The optimization method, namely increasing flat flame burner and radiation plate are conducted and its performance is tested by experiment and computer simulation respectively. The results show that the design of flat flame burners and radiation plate, the temperature uniformity increases significantly to ensure the stability of the engine work, ensuring the Stirling engine heat chamber sufficiently.
\end{abstract}

\section{Introduction}

Stirling engine, also known as heat engine, is an external combustion engine that is, relying on external heat source to seal the refrigerant in the machine heating, a closed cycle, to promote the piston work.Stirling engines have no special requirements for external combustion, as long as the external heat source temperature is higher than the working fluid in the machine, therefore making heating means flexible: you can use fossil fuels, solar energy, biomass, and industrial waste. In addition, Stirling engines also offer to high efficiency, low noise, good operating characteristics, vibration, and reliable and low maintenance costs. Consequently, gas heating device can ensure the heating uniformly of the Stirling engine heat chamber, driving the engine for a long time and stable work,

Abroad have mature solar energy Stirling engine technologies that applied in practice. In China, Stirling engine power generation has mainly in $1 \sim 5 \mathrm{~kW}$. At present, Stirling engines are still using electric heating predominately. Thus the heating power is not enough, and the temperature uniformity is poor, making the engine work difficultly under the rated power ${ }^{[1]}$. This paper propose the method for heating the Stirling engine hot side by natural gas, and puts forward the optimization design method of heating furnace ${ }^{[2]}$.

\section{Materials and methods}

Gas combustion device is used to provide heat source,which is the heart of the gas furnace. The combustion is a key component, because the combustion is directly related to the life of heater and engine working stability. The design of the gas furnace, including the furnace, flat flame burner, radiation plate, back trachea, heat collection chamber, and holder. In order to ensure the performance of the engine under the rated working condition, the flint flame burner and the radiation plate of the combustion furnace are optimized to improve the output power, temperature uniformity of the gas furnace, and the engine hot chamber end for heating. The burner is working as shown in Figure 1. 


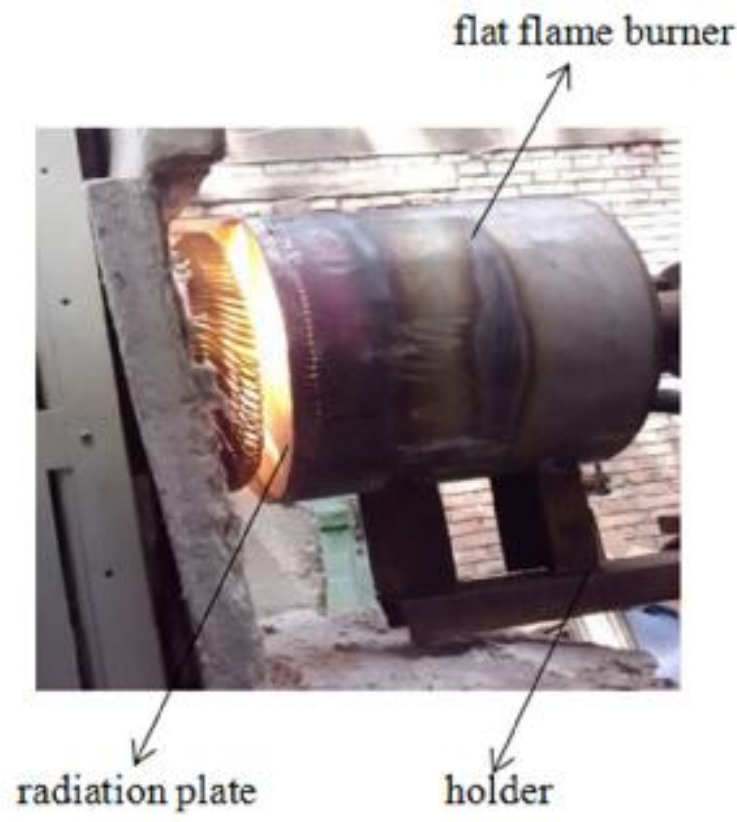

Fig. 1 The burner is working

\section{The use of high-quality flat flame burner}

Compared with the direct flame burner, the flat flame burner is better in flame shape, more uniform and stable in heating, more sufficient in combustion, and higher in flame temperature. Furthermore, flat flame burner can use a variety of gas and fuel oil as fuel ${ }^{[34]}$. The advantages of the flat flame burner are simple structure, convenient maintenance and operation, wide adjusting range, and strong adaptability to fuel and change of air pressure.

Flat flame burning flame is a disk-shaped thin-layer flame. The disk-shaped thin-layer flame arises from rotating centrifugal air flow, with flared flame burner formed. The flame burner consists of burner brick, wind shell, cyclone, natural gas pipeline and other components. This paper applies a porous structure that used to provide high-quality, uniform surface flame.

Compared with the traditional direct flame burner, the flat flame burner has uniform temperature. In this paper, we use tracking method to measure the temperature of the gas furnace through 8 thermocouples with the working temperature at $850 \quad{ }^{\circ} \mathrm{C}$. In order to ensure safety, high temperature resistant metal plate is used to instead of hot end of Stirling engine in the test. Eight temperature sensors are installed on the metal plate to test temperature uniformity. Due to the stable annular flame, the temperature sensors are installed onto a circular layout to detect the uniformity of temperature. The distribution of the thermocouple in the furnace cavity is shown in Fig.2, part of the experimental data as shown in Table 1.

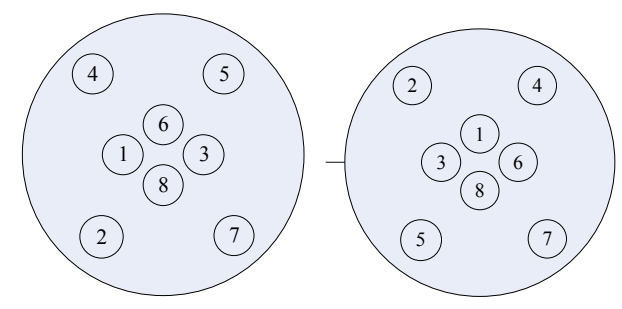

Fig. 2 Thermocouple in the cavity on the distribution 
Table 1 Thermocouple measurement temperature value

\begin{tabular}{ccl}
\hline Thermocouple number & \multicolumn{1}{c}{ 2\# } \\
\hline 1 & $807{ }^{\circ} \mathrm{C}$ & $828{ }^{\circ} \mathrm{C}$ \\
2 & $854{ }^{\circ} \mathrm{C}$ & $813{ }^{\circ} \mathrm{C}$ \\
3 & $814^{\circ} \mathrm{C}$ & $832{ }^{\circ} \mathrm{C}$ \\
4 & $836{ }^{\circ} \mathrm{C}$ & $850{ }^{\circ} \mathrm{C}$ \\
5 & $848{ }^{\circ} \mathrm{C}$ & $865{ }^{\circ} \mathrm{C}$ \\
6 & $823{ }^{\circ} \mathrm{C}$ & $843{ }^{\circ} \mathrm{C}$ \\
7 & $860{ }^{\circ} \mathrm{C}$ & $868{ }^{\circ} \mathrm{C}$ \\
8 & $835^{\circ} \mathrm{C}$ & $854{ }^{\circ} \mathrm{C}$
\end{tabular}

Based on the above experimental results, we obtained that the largest non-uniformity gas furnace temperature coefficient is $6.51 \%$, less than $10 \%$ design requirements.

\section{Increase the radiation plate}

The ideal burner flame is annular and has good uniformity, and the heating temperature is greater than 1200 degrees. In the field test, we found that the direct flame heating belongs to pure convection heat transfer. When the natural gas pipelines absorb the waste gas, which will take away a lot of heat, resulting in low heating power. Meanwhile, through the experimental on a variety of flat flame burner, we found that the flat flame burner is a "black flame" (low temperature of the burner brick center). Therefore, we need to improve the fundamental change of the burner heat transfer mode ${ }^{[5]}$.

Increase radiation plate is an effect measure to ensure transfer heat uniformity. The flame heats the radiant panel, and the radiating plate heats the Stirling engine. The radiating plate is composed of two layers of radiation rods arranged in $90^{\circ}$ phase angle. The radiation rod is made up of a series of high-temperature alloy rods. Flame that is through radiation rod can become more uniformly.

In order to verify the reliability of the scheme, computer simulation is used. After modeling and dividing the mesh, the FLUENT 6.3 is introduced into GAMBIT to carry out simulation experiment ${ }^{[6]}$.The simulation results are shown in Fig.3.
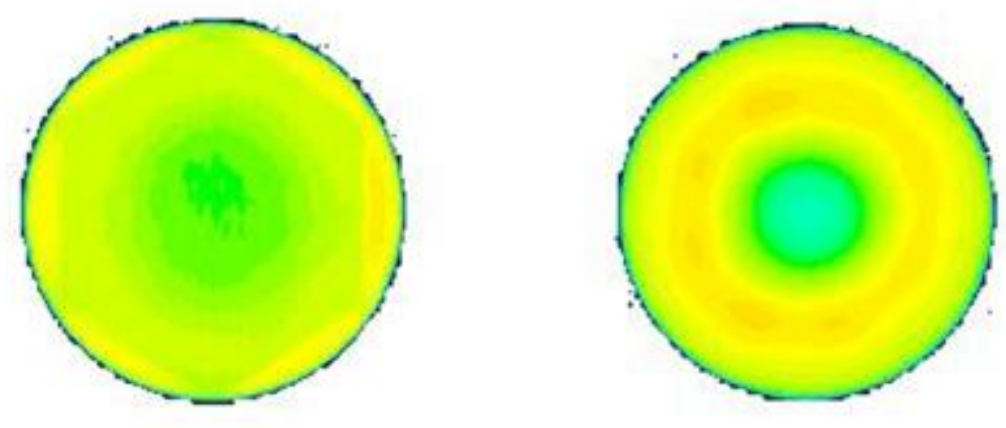

Fig.3 Flame shape comparison

(a) No radiant panel

(b) Add radiant panel

According to the simulation results, it can be seen that under the same combustion conditions, the temperature gradient obviously increases and the uniformity is poor before adding the radiation plate. After adding the radiation plate, the flame is homogenized, and the obvious temperature gradient is eliminated. The simulation results shows that the maximum temperature difference between the maximum and minimum temperature on the radiant panel is not exceeding $100 \quad{ }^{\circ} \mathrm{C}$. 


\section{Efficiency analysis}

According to the design, without additional protective measures and radiation plate case, the engine heating test, the experimental data as shown in the table 2.

Table2 Direct burning heating test data

\begin{tabular}{cccc}
\hline $\begin{array}{c}\text { The Average } \\
\text { temperature of hot } \\
\text { end TB }\left({ }^{\circ} \mathbf{C}\right)\end{array}$ & $\begin{array}{c}\text { The average temperature } \\
\text { of working medium TR } \\
\left({ }^{\circ} \mathbf{C}\right)\end{array}$ & Power $(\mathbf{K W})$ & $\begin{array}{c}\text { Working medium } \\
\text { pressure P2 } \\
(\mathbf{M P a})\end{array}$ \\
\hline 507 & 470 & -4.1 & 6.8 \\
547 & 488 & -5.1 & 7.6 \\
594 & 540 & -8.43 & 9.0 \\
556 & 508 & -6.33 & 9.0 \\
543 & 519 & -8.1 & 10.9 \\
665 & 441 & -7.8 & 11.0 \\
\hline
\end{tabular}

According to the experimental data, when the working medium pressure is $11 \mathrm{MPa}$, the average temperature of the hot end is $665^{\circ} \mathrm{C}$ and the largest working medium average temperature is $441{ }^{\circ} \mathrm{C}$. Under all the above parameters, Stirling engine power can reach about $8 \mathrm{~kW}$.

On the basis of direct fired burner, increasing the radiation board, heating test was carried out on the engine, the experimental data are shown in table 3.

Table3 Increase the radiant panel heating test data

\begin{tabular}{|c|c|c|c|}
\hline $\begin{array}{c}\text { The Average } \\
\text { temperature of } \\
\text { hot end TB }\left({ }^{\circ} \mathrm{C}\right)\end{array}$ & Power (KW) & $\begin{array}{c}\text { Working } \\
\text { medium } \\
\text { pressure P3 } \\
\text { (MPa) }\end{array}$ & $\begin{array}{c}\text { Working } \\
\text { medium } \\
\text { pressure P6 } \\
\text { (MPa) }\end{array}$ \\
\hline 423 & -0.85 & 6.8 & 5.7 \\
\hline 630 & -5.62 & 7.4 & 10.1 \\
\hline 690 & -8.96 & 7.8 & 11.3 \\
\hline 685 & -10.19 & 9.2 & 14.3 \\
\hline 600 & -10.27 & 10.0 & 16.1 \\
\hline 680 & -10.33 & 11.1 & 16.1 \\
\hline 674 & -10.8 & 11.1 & 18.6 \\
\hline 692 & -9.47 & 11.1 & 18.6 \\
\hline 648 & -10.9 & 11.1 & 18.6 \\
\hline 738 & -11.06 & 12.0 & 19.5 \\
\hline
\end{tabular}

According to experimental data, the average temperature of hot end is at $738{ }^{\circ} \mathrm{C}$ when the working fluid average temperature is $563{ }^{\circ} \mathrm{C}$ and working pressure is $11 \mathrm{MPa}$.

The results show that under certain working conditions, the average output power is $8 \mathrm{~kW}$ before increasing radiant panel, while the average output power is $12 \mathrm{~kW}$ after increasing radiant panel, increasing by $50 \%$, so the output power has been improved obviously.

\section{Discussion}

This paper proposes an optimized method which to realize stable operation of Stirling engine and improve the output power of the furnace. The main conclusions in this paper are summarized as follows.

(1)Based on the use of high-quality flat flame burner, flame uniformity can be guaranteed.

(2)The simulation and experimental data verifies the effect of increasing the radiant panel.

(3)The design of flat flame burners and radiation plate, the temperature uniformity increases 
significantly to ensure the stability of the engine work, ensuring the Stirling engine heat chamber sufficiently, also for this kind of burner design and application of scientific method to guide and important reference basis.

\section{Acknowledgements}

This work was supported by Shaanxi science and Technology Department Project (grant number:2016GY-175).

\section{References}

[1] G Chen: Stirling Engine and its application prospect in China. Journal of Agricultural Engineer ing Vol. 07(1993), p.126

[2] Q J Wu: Numerical simulation and optimization of flow, combustion and heat transfer in a hea ting furnace. Changsha: Central South University, 2010.

[3] M C Campos, J V C Vargas and J.C. Ordonez. Thermodynamic optimization of a Stirling engi ne.Energy.Vol. 44(2012), p.902

[4] C J Ding, Y H Jiang, Z P Zheng: Experimental study of several burner. Metallurgical energy. Vol. 07(2004), p.23

[5] Y Guo, W W Cao and P Yan: Natural gas heating furnace structure and heat transfer characte ristics analysis. Journal of Shanghai University of science and technology.Vol. 31(2009), p.251

[6] Z Z Han, J Wang and X P Lan: An example and analysis of fluid engineering simulation and c alculation. Beijing Institute of Technology press, 2004:173-185,201-210 